Article

\title{
Functional Conversion of Acetyl-Coenzyme a Synthase to a Nickel Superoxide Dismutase via Rational Design of Coordination Microenvironment for the $\mathrm{Ni}_{\mathrm{d}}-\mathrm{Site}$
}

\author{
Yaozhu Wei ${ }^{1}$, Yajun Zhou ${ }^{1}$, Hong Yuan ${ }^{1}$, Yi Liu ${ }^{1}$, Ying-Wu Lin ${ }^{2}$, Jihu Su ${ }^{3}$ and Xiangshi Tan ${ }^{1, *}$ \\ 1 Department of Chemistry, Fudan University, Shanghai 200433, China; 12110220023@fudan.edu.cn (Y.W.); \\ 15110220061@fudan.edu.cn (Y.Z.); yuanhong119@163.com (H.Y.); yiliu0825@hubu.edu.cn (Y.L.) \\ 2 School of Chemistry and Chemical Engineering, University of South China, Hengyang 421001, China; \\ ywlin@usc.edu.cn \\ 3 Department of Modern Physics, University of Science and Technology of China, Hefei 230026, China; \\ sujihu@ustc.edu.cn \\ * Correspondence: xstan@fudan.edu.cn
}

Citation: Wei, Y.; Zhou, Y.; Yuan, H.; Liu, Y.; Lin, Y.-W.; Su, J.; Tan, X.

\section{Functional Conversion of}

Acetyl-Coenzyme a Synthase to a Nickel Superoxide Dismutase via Rational Design of Coordination Microenvironment for the $\mathrm{Ni}_{\mathrm{d}}$-Site. Int. J. Mol. Sci. 2022, 23, 2652. https://doi.org/10.3390/ ijms23052652

Academic Editors: Angela Lombardi, Flavia Nastri and Linda Leone

Received: 19 January 2022

Accepted: 21 February 2022

Published: 28 February 2022

Publisher's Note: MDPI stays neutral with regard to jurisdictional claims in published maps and institutional affiliations.

Copyright: (c) 2022 by the authors. Licensee MDPI, Basel, Switzerland. This article is an open access article distributed under the terms and conditions of the Creative Commons Attribution (CC BY) license (https:// creativecommons.org/licenses/by/ $4.0 /)$.

\begin{abstract}
The $\mathrm{Ni}_{\mathrm{d}}$ site coordination microenvironment of a truncated acetyl-coenzyme A synthase has been designed systematically for functional conversion to a Ni-SOD-like enzyme. To this end, the first strategy is to introduce an axial histidine ligand, using mutations F598H, S594H and S594H-GP individually. The resulting three mutants obtained Ni-SOD-like activity successfully, although the catalytic activity was about 10 -fold lower than in native Ni-SOD. The second strategy is to mimic the H-bond network in the second sphere coordination microenvironment of the native Ni-SOD. Two mutations based on F598H (EFG-F598H and YGP-F598H) were designed. The successful EFGF598H exhibited $~ 3-$ fold Ni-SOD-like activity of F598H. These designed Ni-SOD-like metalloproteins were characterized by UV/Vis, EPR and Cyclic voltammetry while F598H was also characterized by $\mathrm{X}$-ray protein crystallography. The $\mathrm{pH}$ titrations were performed to reveal the source of the two protons required for forming $\mathrm{H}_{2} \mathrm{O}_{2}$ in the SOD catalytic reaction. Based on all of the results, a proposed catalytic mechanism for the Ni-SOD-like metalloproteins is presented.
\end{abstract}

Keywords: metalloenzyme; metalloprotein; protein molecular design; acetyl-coenzyme A synthase; $\mathrm{Ni}-\mathrm{SOD}$

\section{Introduction}

The functional diversity of metalloenzymes/metalloproteins is imparted mainly by the incorporated metal centers along with the versatility of the coordination microenvironment, including different oxidation states, metal ion coordination geometry and the hydrogen bonding network in coordination environment [1,2]. Rational design of structural and functional metalloenzymes would greatly advance the field of protein engineering and provide a rigorous test of our knowledge of enzymes [3]. Successful functional conversion of metalloenzymes by molecular design is a challenge to reveal critical structural and mechanistic features that may be concealed in native metalloenzymes [4-10]. Eventually, these features would provide new insights into the functional evolution of metalloenzymes [1-3].

Acetyl-coenzyme A synthase (ACS) catalyzes the synthesis of acetyl-coenzyme A by condensing $\mathrm{CO}$, coenzyme $\mathrm{A}$ and a methyl group from $\mathrm{CH}_{3}-\mathrm{CoFeSP}$ protein at the A-cluster, which consists of a $\left[\mathrm{Fe}_{4} \mathrm{~S}_{4}\right]$ Cubane bridged to a $\left[\mathrm{Ni}_{\mathrm{p}} \mathrm{Ni}_{\mathrm{d}}\right]$ subcomponent via the thiolate of Cys509 [11-13]. The proximal nickel, called $\mathrm{Ni}_{\mathrm{p}}$ site, coordinated to three cysteine thiolates and an unidentified exogenous ligand, is labile and can be removed by treatment with 1,10-phenanthroline (phen). The distal square-planar nickel, called $\mathrm{Ni}_{\mathrm{d}}$ site, utilizes two deprotonated amides and two cysteine thiolates to form a square-planar nickel center $\left[\mathrm{Ni}_{\mathrm{d}} \mathrm{N}_{2} \mathrm{~S}_{2}\right]$ connected to a Cys-Gly-Cys motif. Although the $\mathrm{Ni}_{\mathrm{p}}$ site, as the catalytic 
metal for acetyl-CoA synthesis, has been well-studied, the function of the $\mathrm{Ni}_{\mathrm{d}}$ site is not clear yet, and the $\mathrm{Ni}_{\mathrm{d}}$ is believed to be a redox-inactive metal and remains in the $\mathrm{Ni}^{2+}$ state throughout the catalytic cycle [12].

Nickel superoxide dismutase (Ni-SOD) is also a nickel-containing protein, and its active site in reduced form resembles the $\left[\mathrm{Ni}^{2+} \mathrm{N}_{2} \mathrm{~S}_{2}\right]$ coordination environment of the $\mathrm{Ni}_{\mathrm{d}}$ site of ACS, though they exhibit different properties and functions [14,15]. Ni-SOD is a metalloenzyme that disproportionately superoxides into $\mathrm{O}_{2}$ and $\mathrm{H}_{2} \mathrm{O}_{2}$, and its $\mathrm{Ni}$ center switches between $\mathrm{Ni}^{2+}$ and $\mathrm{Ni}^{3+}$ states during the catalytic cycle. In the reduced state, the $\mathrm{Ni}^{2+}$ adopts a square planar coordination geometry composed of two thiolates, a deprotonated amide nitrogen and the N-terminal amine nitrogen. Upon oxidation, the $\mathrm{Ni}^{3+}$ center is converted to square-pyramidal with His imidazole forming the fifth coordination bond $[14,16]$.

Although the $\mathrm{Ni}_{\mathrm{d}}$ site of ACS resembles the $\left[\mathrm{NiN}_{2} \mathrm{~S}_{2}\right]$ coordination environment in reduced Ni-SOD, it does not exhibit any detectable SOD activity [17]. In this work, we aim to convert the redox-inactive $\mathrm{Ni}_{d}$ site of a truncated ACS into a redox-active Ni-SODlike metalloenzyme. A series of molecular designs have been carried out systematically, based on the redox-inactive $\mathrm{Ni}_{\mathrm{d}}$ site coordination microenvironment of a truncated acetylcoenzyme A synthase, containing the C-terminal 136 residues of ACS (named ACS- $\alpha_{15}$ ) (Figure 1). Considering the difference between the coordination geometry of the $\mathrm{Ni}_{\mathrm{d}}$ site and the oxidized Ni-SOD, it is believed that the axial ligand is indispensable for the stabilization of $\mathrm{Ni}^{3+}$ ions. In our previous work, one mutant, $\mathrm{F} 598 \mathrm{H}$, was designed to introduce an axial histidine ligand to the first coordination sphere of the $\mathrm{Ni}_{\mathrm{d}}$ site, and the mutant protein successfully exhibited Ni-SOD-like activity [17]. Based on the same strategy, two more mutants, S594H and S594H-GP, were also designed and studied herein (Figure 1). These mutant proteins successfully exhibited Ni-SOD-like activity, although the catalytic activity was about $\sim 10$-fold less than that of the native Ni-SOD [18,19]. Based on structural analysis, the low SOD activity of the mutants is mainly due to lack of a favorable hydrogen bond network in the second sphere of the $\mathrm{Ni}_{\mathrm{d}}$ site, although there are many factors that affect SOD activity. The X-ray structure of native Ni-SOD indicates that Tyr9 is involved in hydrogen-bonding with two ordered water molecules in the active site, a common feature in other SODs, which is believed to play a key role in regulating anion access $[14,20]$. Therefore, to better replicate the activity of the native Ni-SOD, the second step of our strategies was to mimic the H-bond network in the second sphere coordination microenvironment of Ni-SOD active site. Two more mutants were then designed and prepared based on the scaffold of F598H (EFG-F598H and YGP-F598H) (Figure 2), and especially the EFG-F598H mutant exhibited a $\sim 3$-fold increased Ni-SOD-like activity of $\mathrm{F} 598 \mathrm{H}$.

These designed Ni-SOD-like metalloenzymes were characterized by UV/Vis, EPR and Cyclic voltammetry. SOD-like activities were analyzed and the structural features responsible for the extraordinary SOD catalytic efficiency were elucidated by $\mathrm{pH}$ titrations and Electro Spray Ionization-Mass Spectroscopy (ESI-MS). The crystal structure of F598H, which contains an inter-molecular disulfide bond, was resolved to explain the impaired SOD activity caused by cysteine oxidation. Finally, the proposed molecular mechanism for the Ni-SOD-like metalloenzymes was presented. 


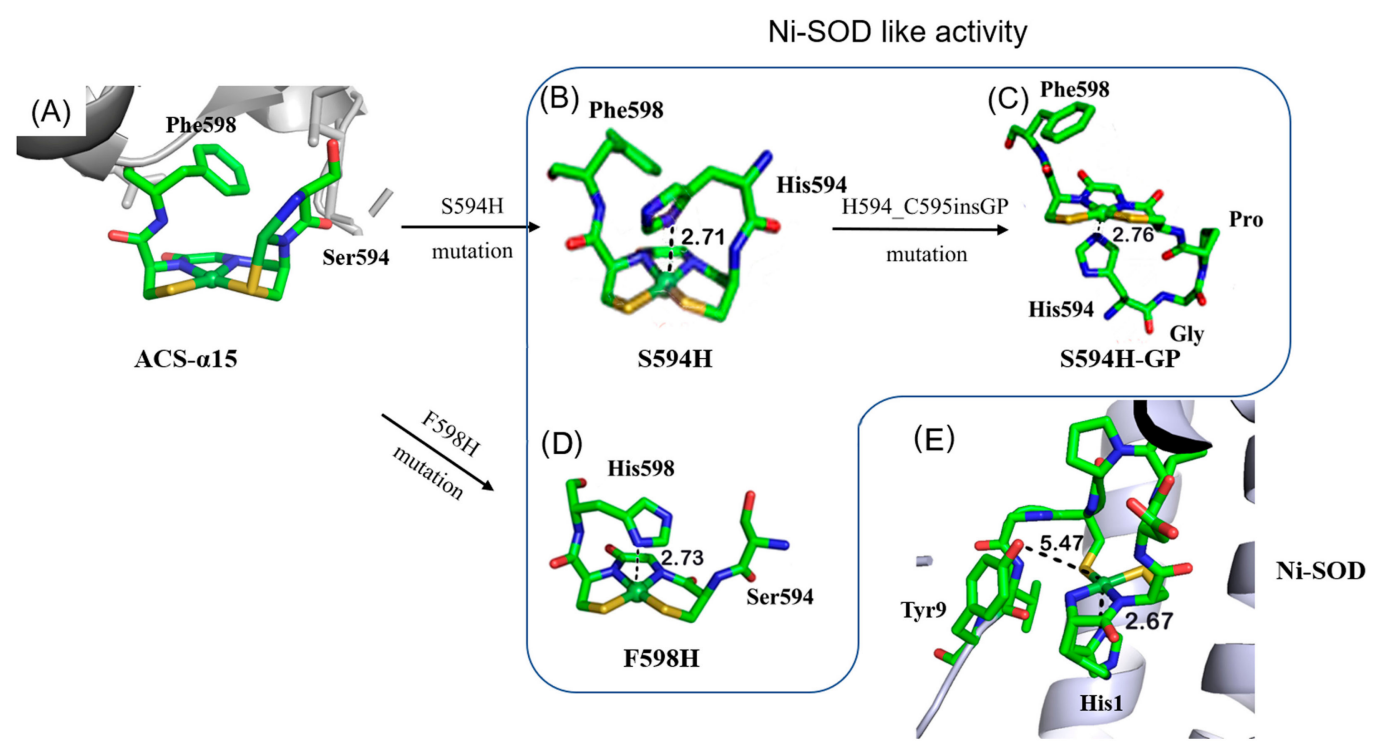

Figure 1. X-ray crystal structure of the truncated ACS protein ACS- $\alpha_{15}$ (PDB: 3S2X, from Moorella thermoacetica.) (A); modeling structure of the designed Ni-SOD-like metalloprotein $\mathrm{S} 594 \mathrm{H}(\mathbf{B})$; $\mathrm{S} 594 \mathrm{H}$ GP (C); F598H (D); and X-ray crystal structure of Ni-SOD (PDB: 1T6U, from Streptomyces coelicolor.) (E).

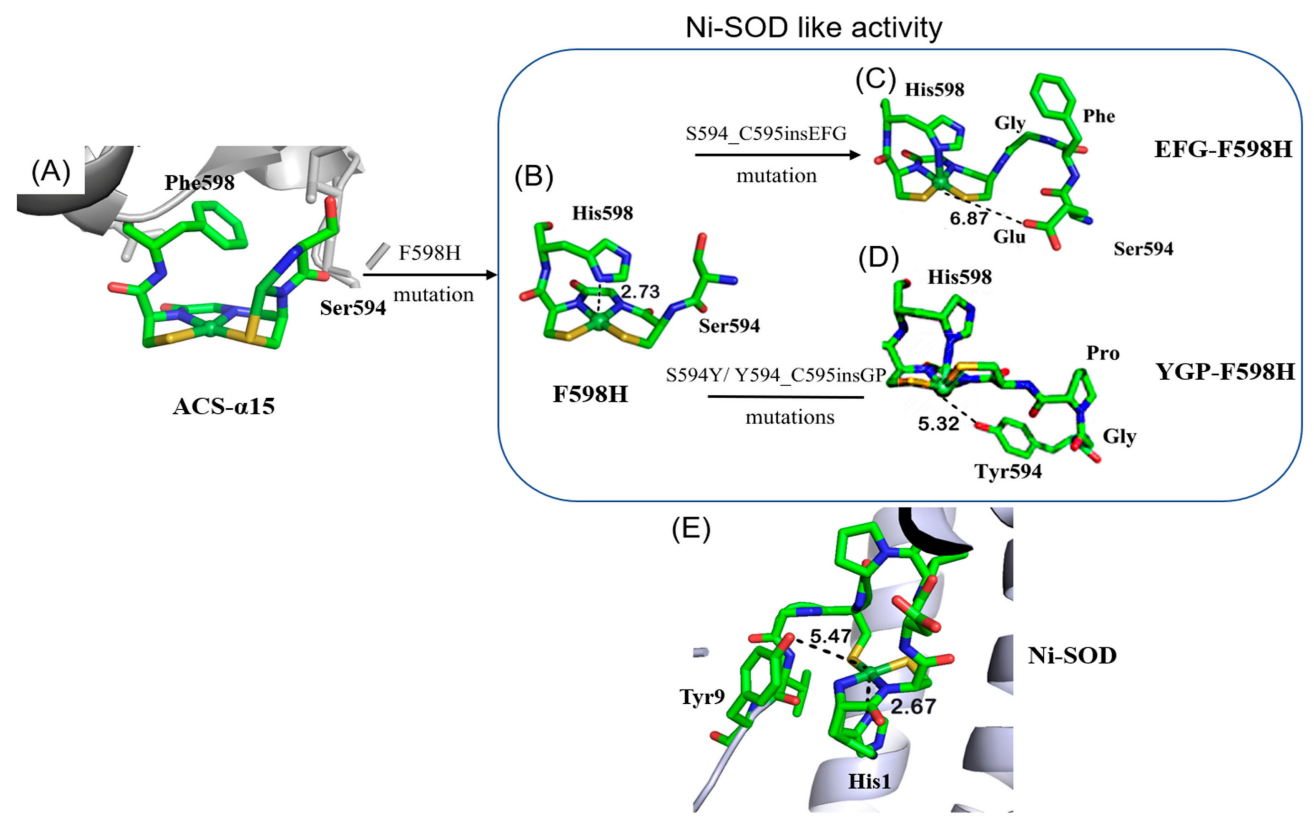

Figure 2. X-ray crystal structure of the truncated ACS protein ACS- $\alpha_{15}$ (PDB: 3S2X) (A); modeling structure of the designed Ni-SOD-like metalloprotein F598H (B); EFG-F598H (C); YGP-F598H (D); and X-ray crystal structure of Ni-SOD (PDB: 1T6U) (E).

\section{Results}

\subsection{Design of Nid-Site by Molecular Modeling}

To design and regulate the coordination microenvironment of the $\mathrm{Ni}_{\mathrm{d}}$ site, an axial Histidine ligand was rationally introduced to the $\mathrm{Ni}_{\mathrm{d}}$ site of ACS- $\alpha_{15}$ based on computer simulation, and the mutant protein, F598H, was successfully shown to have a Ni-SOD-like activity in our previous work [17]. To systematically investigate the influence of the axial His ligand on the Ni-SOD function, several axial His ligands in different positions were introduced to the $\mathrm{Ni}_{\mathrm{d}}$ site in this work. One is $\mathrm{S} 594 \mathrm{H}$, which replaces the $\mathrm{S} 594$ with a His on the basis of ACS- $\alpha_{15}$, and the other is S594H-GP, which inserts two amino acids (Gly and Pro) between His594 and Cys595 on the basis of S594H. Molecular dynamics simulation 
showed that replacement of Ser594 by His could place the $\mathrm{N}_{\delta}$ of His at $\sim 2.71 \AA$ from the nickel ion (Figure 1). On the other hand, by inserting a dipeptide Gly-Pro, S594H-GP could place the $\mathrm{N}_{\delta}$ of His at $2.76 \AA$ from the Ni center in the opposite direction compared to $\mathrm{S} 594 \mathrm{H}$ and $\mathrm{F} 598 \mathrm{H}$ (Figure 1). These distances between the $\mathrm{N}_{\delta}$ of axial His ligand and the $\mathrm{Ni}$ ion are similar to F598H (2.73 $\mathrm{A})$ and the native Ni-SOD (2.67 $⿱$ ) [16]. In the native $\mathrm{Ni}$-SOD active center, there is a key residue Tyr 9 near the vacant coordination site and on the opposite side of the His1 axial ligand, which is thought to play a key role in the catalysis by providing an $\mathrm{H}-$ bond to help in positioning the $\mathrm{O}_{2}{ }^{-}$substrate [20]. Therefore, to better replicate the secondary coordination environment of the nickel ion, two additional mutants, YGP-F598H and EFG-F598H, were designed based on the scaffold of F598H (Figure 2). YGP-F598H refers to a mutant on the basis of F598H, which replaces the S594 with Tyr and then inserts a dipeptide, Gly-Pro, between Try594 and Cys595. EFG-F598H means a variant of $\mathrm{F} 598 \mathrm{H}$, in which a tripeptide, Glu-Phe-Gly, was inserted into the position between Ser594 and Cys595. Molecular modeling studies showed that the introduced Tyr in YGP-F598H lies on the opposite site of axial ligand His598, and is located near the sixth coordination position of the Ni site with a Tyr-O-Ni distance of $5.32 \AA$, which is similar to the distance of Tyr9-O-Ni in native Ni-SOD $(5.47 \AA$ ) $[14,16]$. In the case of EFG-F598H, the carboxyl group of the introduced Glu locates almost in the same plane with the square-planar $\left[\mathrm{NiN}_{2} \mathrm{~S}_{2}\right]$ center with a Glu-O-Ni distance of $6.87 \AA$. (Figure 2).

\subsection{Mutagenesis, Expression, and Purification}

The $\mathrm{F} 598 \mathrm{H}$ variant and all the other derivatives contain the C-terminal 136 residues of ACS, thus apparently retain both the Nip and Nid components, but lack the N-terminal [Fe4S4] cluster. To simplify the purification process and avoid unnecessary amino residues remaining in the $\mathrm{N}$-terminus, a smt3 tag (small ubiquitin-like modifier tag 3 ) gene was inserted into the position between the His tag and $\mathrm{F} 598 \mathrm{H}$ gene. Then, according to the design, the genes of ACS- $\alpha_{15}$, S594H, S594H-GP, EFG-F598H and YGP-F598H with a smt3 tag were constructed by site-directed mutagenesis. All the mutant proteins were efficiently overexpressed with His-smt 3 tags in E. coli. After the SUMO protease cleavage, quantities of the mutant proteins with more than $95 \%$ purity were obtained successfully (Figure S1). All the mutant proteins exhibited a green color similar to $\mathrm{F} 598 \mathrm{H}$ after reconstitution with $\mathrm{NiCl}_{2}$ [17]. Metal analysis indicated that $\mathrm{Ni}$ was the only first row transition metal of significant concentration (Table 1). Gel filtration analysis indicated that all four mutants were present mainly as homodimers following reconstitution with $\mathrm{NiCl}_{2}$, which is similar to ACS- $\alpha_{15}$.

Table 1. UV-Vis and EPR data of ACS- $\alpha 15$ Mutants.

\begin{tabular}{|c|c|c|c|}
\hline \multirow[t]{2}{*}{ Sample } & \multirow{2}{*}{$\begin{array}{l}\text { No. of } \mathrm{Ni} \\
\text { Atoms per Protein }\end{array}$} & $\begin{array}{l}\text { Extinction Coefficient } \\
\qquad\left(\mathbf{M}^{-1} \mathrm{~cm}^{-1}\right)\end{array}$ & \multirow{2}{*}{ EPR } \\
\hline & & $317,430,590 \mathrm{~nm}$ & \\
\hline $\mathrm{F} 598 \mathrm{H}$ & 0.7 & $7760,1495,615$ & $\mathrm{~g}=2.23,2.06,2.00$ \\
\hline S594H & 0.8 & $7065,1565,640$ & $\mathrm{~g}=2.23,2.06,2.00$ \\
\hline S594H-GP & 0.8 & $7685,1490,615$ & $\mathrm{~g}=2.23,2.06,2.00$ \\
\hline EFG-F598H & 0.6 & $7905,1440,695$ & $\mathrm{~g}=2.23,2.06,2.00$ \\
\hline YGP-F598H & 0.5 & $7450,1445,590$ & $\mathrm{~g}=2.23,2.06,2.00$ \\
\hline
\end{tabular}

\subsection{Nickel Binding Study by UV-Vis and ITC}

Electronic absorption spectra of apo- and Ni-reconstituted EFG-F598H are presented in Figure 3 as a representative. The absorption peaks of S594H, S594H-GP and YGP-F598H mutants were extremely similar to EFG-F598H, and almost identical to F598H (Figure S2). Extinction coefficients are summarized in Table 1. The lower energy transitions (430 nm and $590 \mathrm{~nm}$ ) have extinction coefficients consistent with d-d transitions, and the higher energy transition $(317 \mathrm{~nm})$ is most consistent with a transition of charge transfer [21]. 


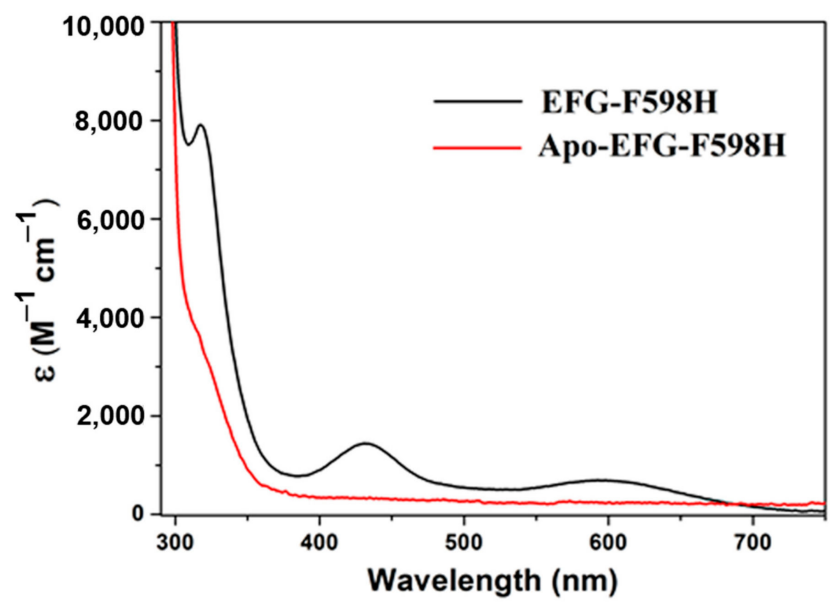

Figure 3. UV-Vis spectra of apo-EFG-F598H (red) and Ni reconstituted EFG-F598H (black).

The electronic absorption around $590 \mathrm{~nm}$ can be assigned to the nonbonding $\mathrm{Ni}\left(3 \mathrm{dz}{ }^{2}\right)$ to $\mathrm{Ni}\left(3 \mathrm{dx} x^{2}-\mathrm{y}^{2}\right) / \mathrm{S} / \mathrm{N}(\sigma)^{*}$ transition, and the one around $430 \mathrm{~nm}$ is due to a $\mathrm{Ni}(3 \mathrm{dxy}) / \mathrm{S}(\pi)^{*}$ to $\mathrm{Ni}\left(3 \mathrm{dx} \mathrm{x}^{2}-\mathrm{y}^{2}\right) / \mathrm{S} / \mathrm{N}(\sigma)^{*}$ transition, which are characteristic of square-planar $\left[\mathrm{NiN}_{2} \mathrm{~S}_{2}\right]$ complexes. Meanwhile, the transition around $317 \mathrm{~nm}$ might be derived from LMCT or an electron transition into the orbital that has higher energy than LUMO. Although it had not been reported before, the absorption around $317 \mathrm{~nm}$ also exists in F598H. These $\mathrm{UV}$-Vis spectral properties indicated that the coordination environment of the $\mathrm{Ni}$ ion in all of these mutants was not significantly perturbed [14]. The coordination environment of the Ni ion in EFG-F598H was further supported for $\mathrm{Ni}$ binding in the right environment by Isothermal Titration Calorimetry (ITC). The calorimetric titration result for titrations of $1.0 \mathrm{mM} \mathrm{NiCl}_{2}$ into a solution of $50 \mu \mathrm{M}$ protein of apo-EFG-F598H are shown in the supporting information (Figure S3). The data correction and curve fitting were performed using Origin 7.0. The curve fit with a one-site sequential binding model well and the $\mathrm{Ni}^{2+}$ affinity constants $\left(K_{d}\right)$ of EFG-F598H is $6.4 \pm 0.5 \mu \mathrm{M}$ (Figure S3).

\subsection{Electron Paramagnetic Resonance}

EPR spectroscopy was used to examine the redox state of the nickel center and probe the electronic structure of the $\mathrm{Ni}$ site. Since all the isolated mutants were in a reduced $\mathrm{Ni}^{2+}$ state, $\sim 1$ equivalent of $\mathrm{KO}_{2}$ was added to trap the oxidized $\mathrm{Ni}^{3+}$ intermediate. The $2 \mathrm{~K}$ EPR spectra of S594H, S594H-GP, EFG-F598H and YGP-F598H were exactly the same and displayed a rhombic $S=1 / 2 \mathrm{Ni}^{3+}$ signal with $g_{x}=2.23, g_{y}=2.06$, and $g_{z}=2.00$ (Table 1 ), indicating a five-coordinate, low-spin $\mathrm{Ni}^{3+}$ center (Figure 4 and Figure S4). These features

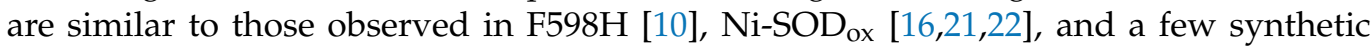
square-pyramidal small molecule complexes [16]. The EPR spectra also revealed a small anisotropic signal at $g_{x}=2.08, g_{y}=2.00$, and $g_{z}=2.00$, which originated from excess $\mathrm{O}_{2}{ }^{-}$ radical [23]. The expected super hyperfine coupling along $g_{z}$ was not detected, which might be due to weak hyperfine interaction between the $\mathrm{Ni}^{3+}$ and the $\mathrm{N}_{\delta}$ of axial His with a relatively long bond distance or was covered by the $\mathrm{O}_{2}{ }^{-}$-radical signal [24,25] (Figure 4).

The EPR data indicated that all these mutants could stabilize the $\mathrm{Ni}^{3+}$ intermediates upon oxidation. The signal of $\mathrm{S} 594 \mathrm{H}$ was stronger than $\mathrm{F} 598 \mathrm{H}$ and similar to Ni-SOD, which might be caused by the smaller distance between His- $\mathrm{N}_{\delta}$ and Ni center. Meanwhile, the EPR spectra of EFG-F598H and YGP-F598H were extremely similar to F598H, which indicated that the electronic structures of the $\mathrm{Ni}^{3+}$ centers were not significantly perturbed by mutations in the second coordination sphere. 


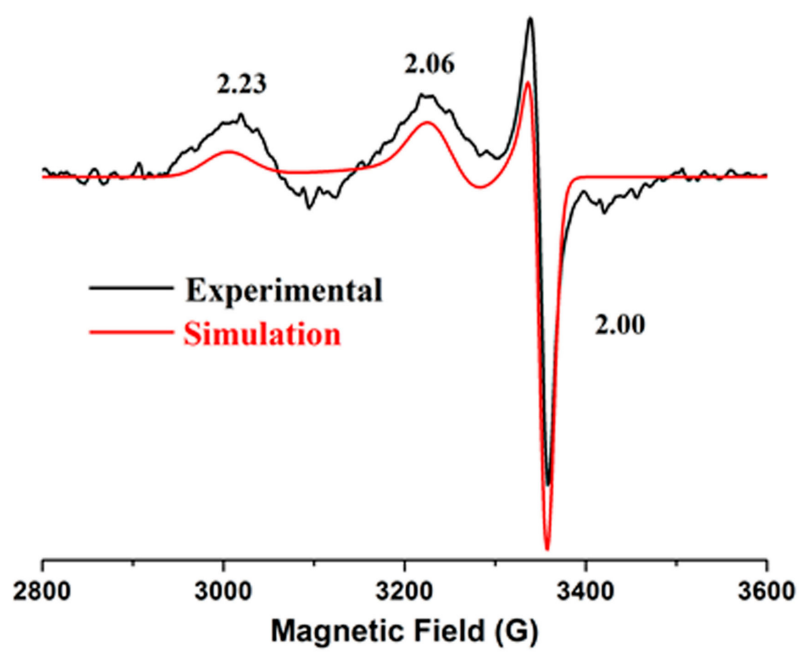

Figure 4. X-band EPR spectrum of EFG-F598H as a representative at $2 \mathrm{~K}$ in the presence of $\sim 1$ equiv of $\mathrm{KO}_{2}$ (microwave frequency, $9.49 \mathrm{GHz}$; microwave power, $20 \mathrm{~mW}$; modulation amplitude, $5 \mathrm{G}$ ). The red line was obtained by simulation.

\subsection{Cyclic Voltammetry}

To determine the redox potential of $\mathrm{Ni}^{2+}$ to $\mathrm{Ni}^{3+}$ transition in the mutants, direct electrochemical measurements were performed using cyclic voltammetry $(\mathrm{CV})$, which is sensitive to the ligand-field environment. A gold electrode modified with a self-assembled monolayer of 3-mercaptopropionic acid (MPA) was used as a working electrode to promote the direct electron transfer [26]. CV curves of S594H, S594H-GP, EFG-F598H and YGP-F598H obtained in a $100 \mathrm{mM}$ phosphate buffer solution (pH 7.0) displayed quasireversible behaviors for the $\mathrm{Ni}^{2+/ 3+}$ redox couple at $\sim 375 \mathrm{mV}$ vs. NHE (Normal Hydrogen Electrode) (Figure 5A and Table 2). The small peak separation of $\sim 70 \mathrm{mV}$ is indicative of one-electron redox progress occurred at the $\mathrm{Ni}$ center. The $E_{\mathrm{m}}$ values are about $200 \mathrm{mV}$ lower than that of $\mathrm{F} 598 \mathrm{H}$ reported before $(570 \mathrm{mV})$ [17], and are closer to that of Ni-SOD $(290 \mathrm{mV})$ [20] and the midpoint $(365 \mathrm{mV})$ for redox couples of $\mathrm{O}_{2} / \mathrm{O}_{2}{ }^{-}(-160 \mathrm{mV})$ and $\mathrm{O}_{2}{ }^{-} / \mathrm{H}_{2} \mathrm{O}_{2}(890 \mathrm{mV})$ [27]. It should be noted that the large different $E_{\mathrm{m}}$ values from F598H may be caused by the different methods used to modify the working electrode. $\mathrm{N}, \mathrm{N}$-dimethyldioctadecylammonium bromide (DDAB) used in previous work may cause F598H partial denaturation. Therefore, the potential of F598H used an MPA-modified gold electrode was redetermined to be $372 \mathrm{mV}$ vs. NHE, which was consistent with the other mutants within the error range.
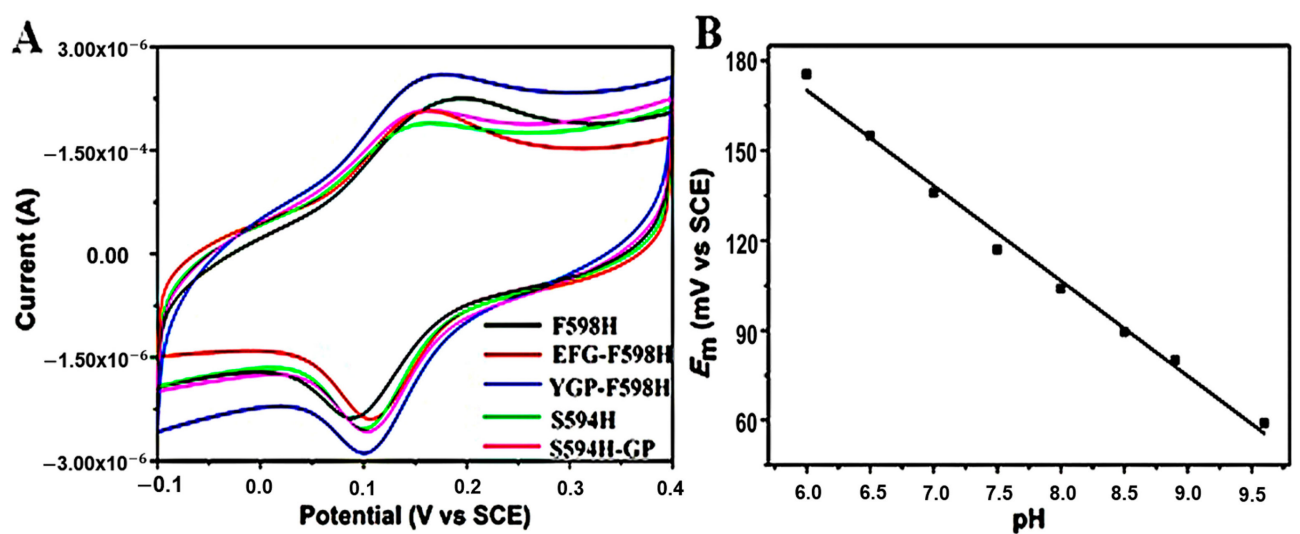

Figure 5. (A): Cyclic Voltammograms at MPA-modified Au electrode in $100 \mathrm{mM}$ PBS ( $\mathrm{pH}=7.0$ ) containing F598H (black), EFG-F598H (red), YGP-F598H (blue), S594H (green) and S594H-GP (pink). Potential scan rate: $100 \mathrm{mV} / \mathrm{s}$; (B): Plots of the formal potentials of EFG-F598H as a representative at the MPA-modified Au electrode vs. solution $\mathrm{pH}$. 
The redox potentials of S594H and S594H-GP were extremely similar to F598H, indicating that all the mutants that introduce an axial ligand have suitable $E_{\mathrm{m}}$ values to catalyze the superoxide disproportionation. Moreover, the $E_{\mathrm{m}}$ values for EFG-F598H and YGP-F598H are also similar to $\mathrm{F} 598 \mathrm{H}$, which indicated that the mutations cannot significantly influence the electron transfer between $\mathrm{Ni}^{2+}$ and $\mathrm{Ni}^{3+}$. These results agree with the observation for Mn-SOD and Ni-SOD, in which mutations of Tyr34 and Tyr9 do not affect the redox potential of the Mn and Ni center [20,28].

In addition, the midpoint potential of EFG-F598H was found to be dependent on the $\mathrm{pH}$ value of the solution (Figure 5B). It decreased linearly with the increasing $\mathrm{pH}$, with a slope of $\sim 30 \mathrm{mV} / \mathrm{pH}$ from $\mathrm{pH} 6.0$ to $\mathrm{pH} 10.0$, indicating two protons and one electron were involved in the electrode reaction of EFG-F598H, which can be characterized by the half-reaction $\mathrm{ENi}^{3+}+\mathrm{e}^{-}+2 \mathrm{H}^{+}=\mathrm{H}^{+}{ }_{2} \mathrm{ENi}^{2+}$ [29]. This observation provides evidence for coupled electron/proton-transfer reactions at the active site [30].

\subsection{SOD Activity}

One focus of this study is to investigate whether the activity of the mutants was regulated by the designed microenvironment of the Ni site. Table 2 summarizes the catalytic rate constants (Figure S5) for all these mutants [20]. S594H and S594H-GP display a little higher activity than F598H. EFG-F598H exhibits a considerably enhanced activity, which is $\sim 3$-fold higher than that of $5598 \mathrm{H}$, while $\sim 3$-fold lower than that of native NiSOD from $S$. coelicolor $(45,292 \mathrm{U} / \mu \mathrm{M})[18,31]$. Meanwhile, the catalytic activity of YGP$\mathrm{F} 598 \mathrm{H}$ is only $\sim 80 \%$ of F598H (Table 2 and Figure 6 ). These results demonstrated that the residues designed to form a second coordination sphere are intimately involved in the catalytic reaction.

Table 2. $E_{\mathrm{m}}$ and SOD activity (pH 7.5) of ACS- $\alpha 15$ Mutants.

\begin{tabular}{cccc}
\hline Sample & $\begin{array}{c}\text { No. of Ni Atoms } \\
\text { per Protein }\end{array}$ & $\boldsymbol{E}_{\mathbf{m}}(\mathbf{m V}$ vs. NHE) & $\begin{array}{c}\text { SOD } \\
\text { Activity (U/ } \boldsymbol{\mu m o l )}\end{array}$ \\
\hline F598H & 0.7 & 372 & 4360 \\
S594H & 0.8 & 374 & 4940 \\
S594H-GP & 0.8 & 375 & 4600 \\
EFG-F598H & 0.6 & 377 & 14,770 \\
YGP-F598H & 0.5 & 374 & 3420 \\
\hline
\end{tabular}

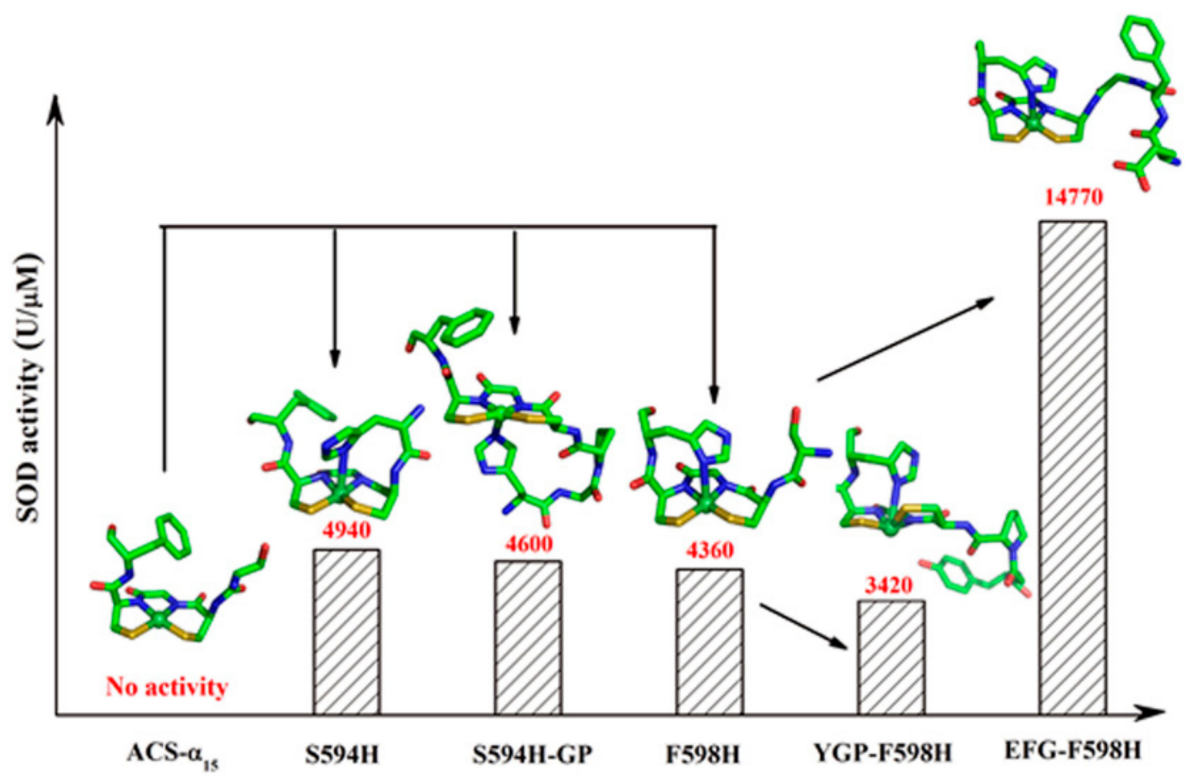

Figure 6. SOD-like activity with structures of the truncated ACS protein ACS- $\alpha 15$ (PDB: 3S2X) and modeling structures of S594H, S594H-GP, F598H, YGP-F598H and EFG-F598H. 


\subsection{Effect of $\mathrm{pH}$ on SOD Activity}

Since $\mathrm{pH}$ can influence the visible absorption of SOD [32,33], its effects on the designed Ni-SOD-like enzymes were observed. The $\mathrm{pH}$-dependent absorption changes at $430 \mathrm{~nm}$ are shown in Figure S6. The Henderson-Hasselbalch equation for a single $\mathrm{pK}$ was used to fit the curves. All the $\mathrm{p} K_{\mathrm{a}}$ values were determined to be 7.3 , which was believed to be identical within experimental error. As $430 \mathrm{~nm}$ is defined as characteristic absorption of square-planar $\left[\mathrm{NiN}_{2} \mathrm{~S}_{2}\right]$ complexes, the changes could be caused by the protonation of His598-N, Cys595-S/Cys597-S or $\mathrm{H}_{2} \mathrm{O}$ bonded around the Ni center. As ACS $\alpha_{15}$, which lacked the axial histidine ligand, displayed a similar $\mathrm{p} K_{\mathrm{a}}$ to other three mutants, the $\mathrm{p} K_{\mathrm{a}}$ at 7.3 can be attributed to the protonation of Cys595/Cys597 or $\mathrm{H}_{2} \mathrm{O}$.

As reported previously, the activity of native Ni-SOD is $\mathrm{pH}$ dependent, which is similar to other SODs, particularly Mn-SOD [27,32]. In this study, the rate constants of F598H, EFG$\mathrm{F} 598 \mathrm{H}$ and $\mathrm{YGP}-\mathrm{F} 598 \mathrm{H}$ were determined at different $\mathrm{pH}$ values. The catalytic rate constants changed as a function of $\mathrm{pH}$ revealed two $\mathrm{pH}$ transitions, with $\mathrm{p} K_{\mathrm{a}} \mathrm{s}$ equal to $\sim 6.0$ and $\sim 7.4$ (Figure 7). According to the result of direct electrochemistry, the reduced enzymes are believed to supply two protons for the reaction to form $\mathrm{H}_{2} \mathrm{O}_{2}$. Therefore, the $\mathrm{p} K_{\mathrm{a}} \mathrm{s}$ observed in the SOD activity measurements can be attributed to the protonation/deprotonation of the ligands that supply protons for the reaction. As we know, the $\mathrm{p} K_{\mathrm{a}}$ value of free histidine is 6.04, which is consistent with the observed lower $\mathrm{p} K_{\mathrm{a}}$ value. So, one of the protons required for the catalytic cycle probably comes from His598, which can coordinate to the oxidized $\mathrm{Ni}$ center and does not interfere with the absorption spectra of the reduced $\mathrm{Ni}$ center. Besides, the similarity between the higher $\mathrm{p} K_{\mathrm{a}}$ in SOD activity measurements and the optical $\mathrm{p} K_{\mathrm{a}}$ suggests that these two values correspond to the same event. Hence, the second proton may come from Cys595/Cys597 or $\mathrm{H}_{2} \mathrm{O}$ bonded around the Ni center. This result is different from the previous reports of Ni-SOD, which always has one $\mathrm{p} K_{\mathrm{a}}$ [27]. However, the different $\mathrm{Ni}$ center structure and different mechanism of protons transfer may rationalize these observations.
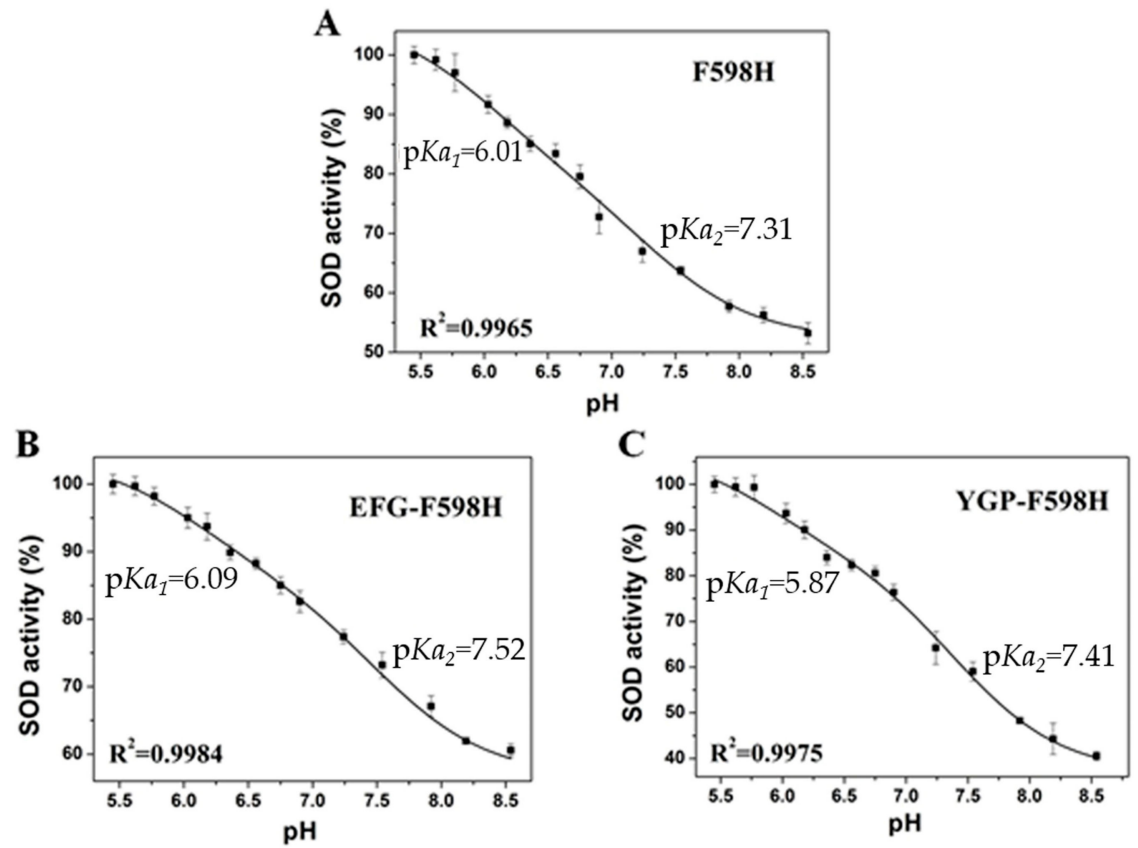

Figure 7. The effect of $\mathrm{pH}$ changes on the rate constants for the enzyme reaction of $\mathrm{F} 598 \mathrm{H}$ (A), EFG-F598H (B), and YGP-F598H (C).

Moreover, the secondary structure alteration of EFG-F598H induced by $\mathrm{pH}$ changing was examined by monitoring the ellipticity at $222 \mathrm{~nm}$ of circular dichroism spectra. As shown in Figure S7, no apparent change in ellipticity values was noticed across a $\mathrm{pH}$ range of 5 to 10, which indicated pronounced stability of EFG-F598H against $\mathrm{pH}$ changing. This 
result proved that the $\mathrm{pH}$-dependent changes observed above were indeed caused by the protonation/deprotonation of the His, Cys or $\mathrm{H}_{2} \mathrm{O}$ coordinated to the active-site nickel, which provides clues for underlying dismutation mechanism of these NiSOD-like enzymes, especially for the protons' source.

\subsection{Electro Spray Ionization-Mass Spectroscopy (ESI-MS)}

It was reported that a bisamidate donor within $\left[\mathrm{Ni}^{2+} \mathrm{N}_{2} \mathrm{~S}_{2}\right]$ complexes would lead to relatively rapid thiolate ligand oxidation under aerobic conditions and yield a terrible defective activity $[24,34,35]$. In order to find out the relationship between the inner sphere coordination environment and defective activity, ESI-MS, a powerful analytical technique allowing quantitative analysis of S-oxidated-proteins, was performed. All the mutants were expressed and purified under aerobic conditions, and the ESI-MS analysis showed that the measured molecular weight of EFG-F598H is $15,054.9 \mathrm{Da}$, which is consistent with the theoretical value $(15,057.3 \mathrm{Da})$, indicating no evidence of oxidative modification. In stark contrast, the measured molecular weights of F598H and YGP-F598H are 14,694.3 Da and $14,925.8 \mathrm{Da}$, respectively, which are 32 Da greater than the theoretical value $(14,666.9 \mathrm{Da}$ and 14,897.2 Da) (Figure S8). This phenomenon suggests that aerobic conditions can yield extensive oxidative modification to these two mutants. The extra $32 \mathrm{Da}$ is due to the insertion of two oxygen atoms, corresponding to the oxidization of one thiolate ligand to a coordinated sulfinate, as in the metallopeptide-based mimics [35].

These observations suggest that EFG-F598H can protect the nickel center from oxidation, whereas F598H and YGP-F598H cannot, which may rationalize that EFG-F598H has a relatively higher catalytic activity.

\subsection{Crystal Structure of $F 598 \mathrm{H}$}

In the course of the study, it was found that $\mathrm{F} 598 \mathrm{H}$ purified under aerobic conditions without the reductant had a lower activity than those purified in the presence of the reductant. To explain this phenomenon, non-reduced SDS-PAGE and gel filtration chromatography were performed to analyze the component of F598H. The non-reduced SDS-PAGE system does not contain any reductant that could destroy disulfide bonds, so that it can distinguish the components that contain inter-molecular disulfide bonds. The results showed that a small part of F598H was present in the form of dimer and even tetramer caused by inter-molecular disulfide bonds. When the reductant, Tris(2-carboxyethyl) phosphine (TCEP), was added to the protein, the tetramer of F598H disappeared, and the dimer also reduced (Figure S9A). The results of gel filtration chromatography were identical. F598H purified under aerobic conditions without the reductant displayed a main peak for the dimer and accompanied by a shoulder, whose molecular weight was consistent with a tetramer F598H. However, F598H purified with reductant, which was verified to contain no inter-molecular disulfide bond by non-reduced SDS-PAGE, did not display the tetramer shoulder peak (Figure S9B). These results indicated that absence of the reductant indeed led to the formation of an inter-molecular disulfide bond, which might be the reason for the decreased activity.

To confirm this result above, a $2.20 \AA$ resolution structure of F598H that contained intermolecular disulfide bond was determined under aerobic conditions. In the crystal structure (PDB: 5GOL), there were four asymmetric molecules. Each two molecules were connected by one disulfide bond to form a pair. Each pair of molecules contained two nickel metal centers. Two F598H subunits were found to form a dimer, while the nickel binding sites were located at the dimer interface. The structure diagram revealed that the two subunits interacted with each other through one disulfide bond (Figure 8). The structural alignment indicated that the overall structure of $F 598 \mathrm{H}$ was similar to ACS- $\alpha_{15}$ with a root-meansquare deviations (RMSD) of $0.36 \AA$, indicating that mutation of Phe598 to His598 did not affect the correct folding of F598H (Figure S10) [36]. 


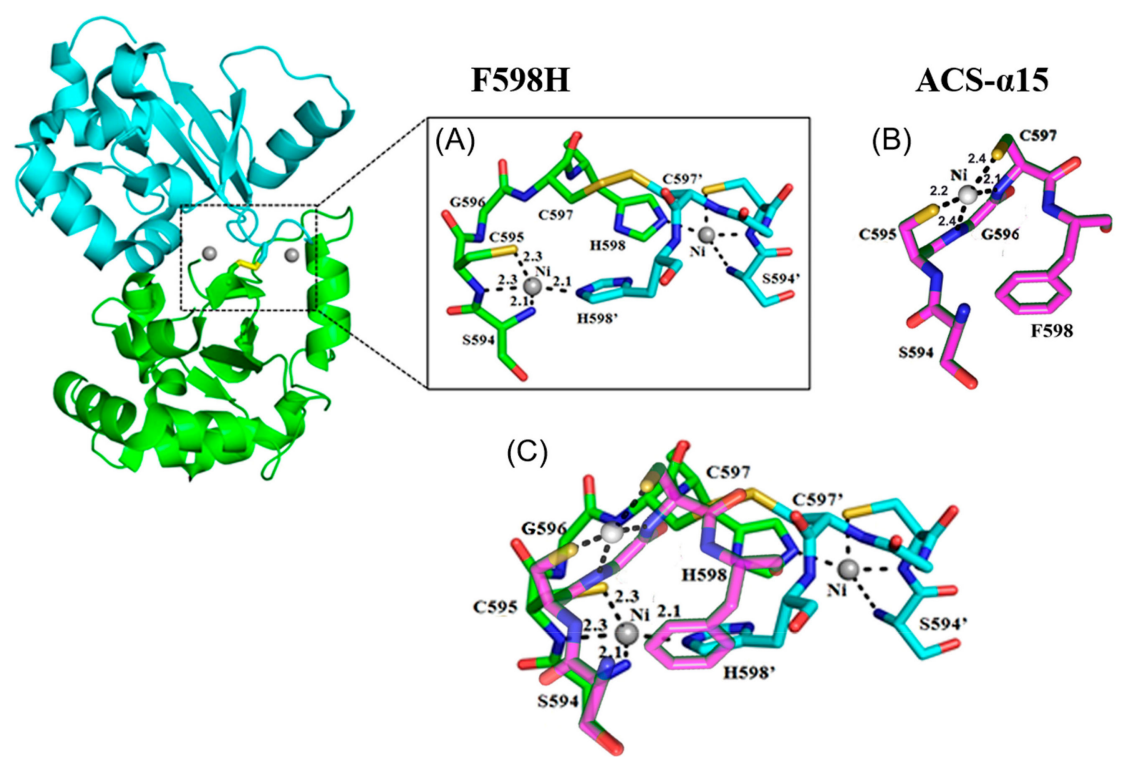

Figure 8. Overall structure of F598H (PDB: 5GOL) purified under aerobic condition and the nickel binding sites. (A) structure of the Ni metal center in $\mathrm{F} 598 \mathrm{H}$, Chain A colored by green, Chain B colored by cyan; (B) Ni metal center in ACS- $\alpha_{15}$ (PDB: 3S2X), colored by purple; (C) Superposition of F598H (green) and ACS- $\alpha_{15}$ (purple). Ni in grey, $\mathrm{S}$ in yellow, $\mathrm{O}$ in red and $\mathrm{N}$ in blue.

In the "active center" of $\mathrm{F} 598 \mathrm{H}$, the only $\mathrm{Ni}$ atom was located at the $\mathrm{Ni}_{\mathrm{p}}$ * site as mentioned in ACS- $\alpha_{15}$ and was coordinated by one N-terminal $\mathrm{NH}_{2}$ (Ser594) with a distance of $2.1 \AA$, one backbone amide $\mathrm{N}$ atom of Cys595 (2.1 $\AA$ ), one cysteine $\mathrm{S}$ atom of Cys595 (2.3 $\AA$ ) and one imidazole $\mathrm{N}$ atom of His598 (2.3 $\AA$ ) from another F598H subunit (Figure 8). However, the designed active metal center, which should be located on the $\mathrm{Ni}_{\mathrm{d}}$ site, was absent. This must be due to the formation of an inter-molecular disulfide bond between two Cys597, which is a key residue coordinated to the $\mathrm{Ni}_{\mathrm{d}}$ center. As the $\mathrm{Ni}_{\mathrm{p}}$ * center lacks the fifth axial ligand, it is also impossible to have any Ni-SOD activity. So, the crystal structure indicated a F598H without SOD activity, which could explain the impaired SOD activity.

\section{Discussion}

Based on the structural analysis, two obvious differences existed the Ni-site between the truncated ACS- $\alpha_{15}$ and native Ni-SOD. The Ni $\mathrm{d}_{\mathrm{d}}$-site of ACS- $\alpha_{15}$ lacks axial histidine ligand in the nickel coordination geometry and is without the H-bond network in the coordination microenvironment. Histidine nitrogen deprotonation upon metal ion coordination can afford negative charges to stabilize metal ions in higher oxidation states (e.g., $\mathrm{Ni}^{3+}$ and $\mathrm{Fe}^{3+}$ ) [37-39]. Upon oxidation, the $\mathrm{Ni}^{3+}$ active site coordination geometry in Ni-SOD is converted from square-planar to square-pyramidal with His1 fifth coordination bond. It was shown that when the axial His ligand in the Ni-SOD was removed or substituted with Asp or Ala, the catalytic activity was impaired, which indicated the critical role of the axial His ligand $[22,40]$. However, the $\mathrm{Ni}_{\mathrm{d}}$-site of ACS- $\alpha_{15}$ lacks an axial histidine ligand, therefore it remains in the $\mathrm{Ni}^{2+}$ state and the $\mathrm{Ni}^{3+}$ state cannot be captured even in the presence of strong oxidants. For functional conversion of ACS- $\alpha_{15}$ at the $\mathrm{Ni}_{\mathrm{d}}$ site to a Ni-SOD-like enzyme, molecular designs have been implemented using molecular dynamic simulations. An axial histidine ligand was introduced by the mutations (F598H, S594H and S594H-GP individually), to the first coordination geometry of the $\mathrm{Ni}_{\mathrm{d}}$ site. The resulting three mutant proteins were successfully converted into functional Ni-SOD-like enzymes, and the role of axial histidine ligand in stabilizing $\mathrm{Ni}^{3+}$ at the $\mathrm{Ni}_{\mathrm{d}}$ site has been confirmed. UV-vis spectra of the mutants indicated that the square-planar coordination environment of the $\mathrm{Ni}_{\mathrm{d}}$ site was not disturbed in reduced states. EPR spectra of the designed mutants testified that the axial ligand had the ability to form the fifth coordination bond and stabilize the $\mathrm{Ni}^{3+}$ 
ion. Moreover, S594H exhibited a more intensive EPR signal than F598H, which might be in line with its higher activity. Additionally, the suitable $E_{\mathrm{m}}$ values of the mutations provided further evidence for their Ni-SOD-like activity. However, the SOD activity of the designed mutants is lower than that of native Ni-SOD, which may be due in part to lacking the suitable $\mathrm{H}$-bond network in the coordination microenvironment of the $\mathrm{Ni}_{\mathrm{d}}$ site.

In native Ni-SOD, Tyr9 lies near the vacant sixth coordination position, and is in opposite position of the His1 axial ligand, with a Ni-O (Try9) distance of $5.47 \AA$. The phenol proton of Tyr9 is believed to involve the hydrogen bonds network with two ordered water molecules [14,16,27]. The Tyr 9 residue is thought to play a key role in the catalysis by providing a H-bond to regulate anion access [20]. Thus, to further improve the SOD activity and to study the catalytic mechanism of Ni-SOD based on these NiSOD-like enzymes, another two mutants, EFG-F598H and YGP-F598H, were designed, which better replicated the secondary sphere coordination microenvironment of the $\mathrm{Ni}_{\mathrm{d}}$ site. As characterized by UV-Vis and EPR studies, F598H, EFG-F598H and YGP-F598H have very similar UV-Vis and EPR features, which indicated that introducing a hydroxyl around the metal center does not disturb the structure of the $\mathrm{Ni}_{\mathrm{d}}$ site in either the reduced or oxidized state. Moreover, extremely similar potentials were obtained for these mutants by direct electrochemical measurement, which indicated that the mutations do not significantly influence the electron transfer in the redox process required for catalyzing the $\mathrm{O}_{2}{ }^{-}$disproportionation reaction. Although these mutants have similar spectral properties and redox potentials, distinct SOD activities were exhibited. EFG-F598H has $\sim 300 \%$ enhanced activity compared to F598H, whereas YGP-F598H only has 60\% activity compared to F598H. These observations demonstrated that the residues introduced in the coordination microenvironment are intimately involved in the redox reaction.

To understand how these mutant enzymes participate in the disproportionation reaction and thus how they influence the activities, the catalytic mechanism was investigated. Until now, at least three controversies still exist in the catalytic mechanism of Ni-SOD: where the two protons needed for the reaction come from; if the substrate binds to the Ni center directly; and from which direction the substrate approaches the active center. Firstly, a series of $\mathrm{pH}$ titrations were performed to determine the two protons needed for the formation of $\mathrm{H}_{2} \mathrm{O}_{2}$. The results of $\mathrm{CV}$ titration indicated that two protons and one electron were involved in the electrode reaction, and the two protons should be supplied by residues around $\mathrm{Ni}_{\mathrm{d}}$ center or some small molecule bonded around the $\mathrm{Ni}_{\mathrm{d}}$ center, such as $\mathrm{H}_{2} \mathrm{O}$. The results of UV-vis absorption titration inferred that one of the protons came from Cys595/Cys597 or $\mathrm{H}_{2} \mathrm{O}$ bonded around the Ni center. Besides, the results of SOD activity rate titration confirmed the conclusion of UV-vis absorption titration and also revealed that the other proton came from the axial histidine. This result is similar to a previous calculated report of Ni-SOD [41]. Secondly, to confirm if the substrate binds to the Ni center directly, anions such as azide ion and thiocyanide ion were added to the reaction system. SOD activity change was not found, which supported an outer-sphere redox reaction for both half-reactions. Lastly, the SOD activity of the mutants, in which negatively charged residue was introduced to the opposite site of the axial ligand, was analyzed to determine the attack direction of the substrates. As the results showed, the SOD activity of YGP-F598H $(3420 \mathrm{U} / \mu \mathrm{M})$ was lower than that of $\mathrm{F} 598 \mathrm{H}(4360 \mathrm{U} / \mu \mathrm{M})$, which might be due to the electrostatic repulsion between the introduced negatively charged residue and substrates. This phenomenon also existed in another two mutants, S594H-GP-F598Y (2100 U/ $\mu \mathrm{M})$ and S594H-GP-F598D (2740 U/ $\mu$ M) (Figure S11). So, it is believed that the substrates would attach the $\mathrm{Ni}$ site from the opposite direction of the axial ligand.

Therefore, an outer-sphere catalytic mechanism for the Ni-SOD-like mutants based on $\mathrm{Ni}_{\mathrm{d}}$-site of ACS- $\alpha_{15}$ is proposed (Figure 9). At the beginning of the reaction (State I), the mutant enzyme is in His-off $\mathrm{Ni}^{2+}$ state with protonated histidine and cysteine $/ \mathrm{H}_{2} \mathrm{O}$. The superoxide anion attacks the Ni site from the opposite site of the histidine axial ligand (State II). Then, electron transfer occurs concomitant with proton transfers, leading to formation of peroxide and His-on $\mathrm{Ni}^{3+}$ state with deprotonated histidine and cysteine $/ \mathrm{H}_{2} \mathrm{O}$. 
With the end of the first half reaction, the second half reaction starts immediately (State III). Superoxide also approaches the nickel center from the opposite position of the histidine axial ligand (State IV). With the transfer of the electron, an oxygen molecule and a His-off $\mathrm{Ni}^{2+}$ state are yielded. At the same time, the mutant proteins obtain two protons from the solvent, and protonated histidine and cysteine $/ \mathrm{H}_{2} \mathrm{O}$ are formed again (State I). Hereto, a catalytic cycle is completed.

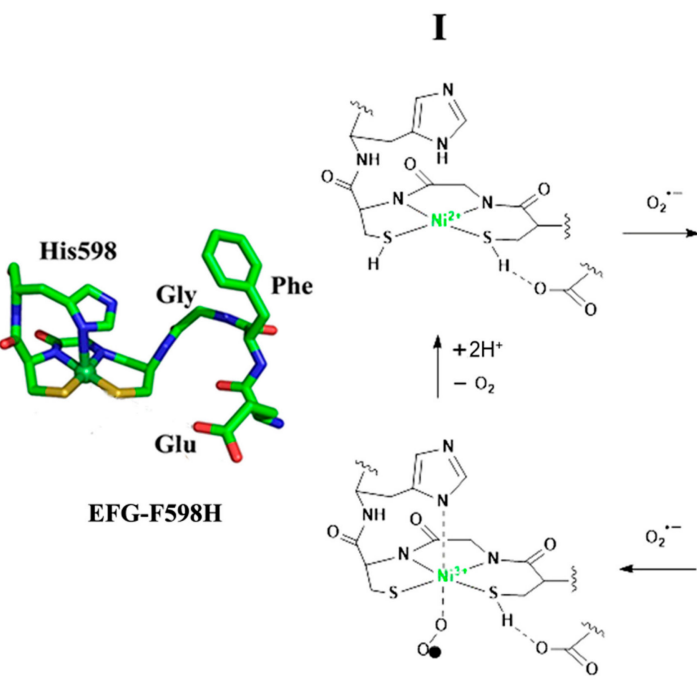

IV
II
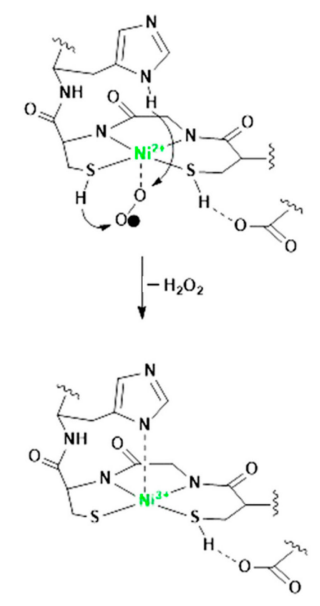

III

Figure 9. Proposed Outer-Sphere Catalytic Mechanism for EFG-F598H. State I: the begin of the reaction; State II: superoxide anion attacks the Ni site, the first half reaction; State III: His-on $\mathrm{Ni}^{3+}$ state; State IV: Superoxide also approaches the nickel center, the second half reaction.

Although a mechanism for the Ni-SOD-like mutants based on the $\mathrm{Ni}_{\mathrm{d}}$-site of ACS- $\alpha_{15}$ is proposed, the high SOD activity of EFG-F598H still cannot be understood well. Therefore, the active metal centers of the mutants and native Ni-SOD are analyzed again. Although ACS-Ni $i_{d}$ displays a similar square-planar coordination environment to reduced Ni-SOD, there is still a difference between these two sites. The nickel ion in Ni-SOD contains a mixed amine/amidate coordination motif, whereas the $\mathrm{Ni}_{\mathrm{d}}$ site in ACS- $\alpha_{15}$ contains a bis-amidate coordination motif. It was reported that a bis-amidate donor within $\left[\mathrm{Ni}^{2+} \mathrm{N}_{2} \mathrm{~S}_{2}\right]$ complexes could lead to relatively rapid thiolate ligand oxidation under electrophilic attack by $\mathrm{O}_{2}$ and reactive oxygen species (ROSs) [35]. However, the combination of amine and amidate donors-set could also yield a stable nickel center under identical conditions, and such oxidation events could yield a terrible defective activity [35]. Despite these observations, the mutants of truncated ACS- $\alpha_{15}$ in this study still keep a relatively high activity, even though they all have bis-amidate ligands, which is different from that of the nickel-containing metallopeptide-based Ni-SOD mimics [24,34]. To address this issue, ESI-MS was used to analyze the mutant enzymes expressed and purified under aerobic conditions. As evidenced by ESI-MS, both F598H and YGP-F598H were extensively modified by insertion of two oxygen atoms. Similar to the observation for metallopeptide-based mimics, these results correspond to the oxidized of one thiolate ligand to a coordinated sulfinate [35]. Surprisingly, EFG-F598H has the MW expected for the amino acid substitutions involved, suggesting no thiolate ligand has been oxidized under aerobic conditions, which is consistent with a higher catalytic activity. As EFG-F598H and $\mathrm{F} 598 \mathrm{H}$ are identical in the inner sphere coordination, the protective effect of the thiolate ligand might be due to the effect of the second coordination sphere, hydrogen bonding and/or steric interactions. Molecular dynamic simulation showed that the glutamate introduced in EFG-F598H was flexible and the distances between the Glu-O and Cys595/597-S were 4.62/6.46 $\AA$, which was most likely involved in the hydrogen bonds network with the protonation of thiolate ligand. However, YGP-F598H cannot protect the thiolate ligand from oxidation, which might be 
attributed to inappropriate steric interactions. The phenol oxygen of Tyr in YGP-F598H is far away from both the sulfur atoms with distances of $\sim 7 \AA$, and because of the presence of proline, the tyrosine is not as flexible as glutamate in EFG-F598H. Therefore, it is difficult for YGP-F598H to form an H-bond with cysteine.

Besides, another situation that can affect the activity of the Ni-SOD-like enzymes was observed. When the reductant is absent in the purification system, a small part of the key cysteine residues that should coordinate to the active Ni center will be oxidized to form inter-molecular disulfide bonds. The results of crystal structure indicated that these disulfide bonds lead to the deficiency of the active $\mathrm{Ni}_{\mathrm{d}}$ center, and thus cause the loss of Ni-SOD activity. Even so, Ni-SOD-like enzymes still have enhanced catalytic activities compared with small molecules and metallopeptide Ni-SOD mimics, which should be attributed to the protective effect on the active Ni center and the stereo regulation of the substrate access by the protein side chain.

\section{Materials and Methods}

\subsection{Materials}

Pfu DNA polymerase, T4 DNA ligase, dNTP, and restriction enzymes (Nde I, and Xho I) were purchased from New England Biolabs. The KOD-Plus Mutagenesis Kit was purchased from TOYOBO. The E. coli strains Trans 10 and BL21(DE3) PlysS were obtained from TransGen. The plasmid purification kits, gel extraction kits, nickel nitrilotriacetic acid resin and Sephadex G-25 resin were purchased from QIAGEN (Chatsworth, CA, USA). The SuperdexTM 200 HiLoad 16/60 gel filtration column was from Pharmacia. The xanthine, xanthine oxidase and NBT were obtained from Sigma (St. Louis, MO, USA). The $\mathrm{KO}_{2}$ was purchased from Acros. All other reagents were of analytic grade.

\subsection{Cloning, Expression, and Purification}

F598H was cloned similarly as described [17], but the cloning detail method was modified by inserting a smt3 gene tag between the His tag and F598H. The F598H variant and all other derivatives contain the C-terminal 136 residues of ACS thus apparently retain both the Nip and Nid components, but lack the $\mathrm{N}$-terminal $\left[\mathrm{Fe}_{4} \mathrm{~S}_{4}\right]$ cluster. Overlap extension PCR was used. In the first round of PCR, the primers P1 and P2 were used to amplify the smt3 and F598H genes, respectively. Then the purified PCR products were used as the templates in the second round PCR, using primers P1-F and P2-R. The resulting PCR product digested with Nde I and Xho I was inserted into a pET-28b (+) vector. Based on the His-smt3-F598H template, EFG-F598H and YGP-F598H were constructed by the KOD-Plus Mutagenesis Kit (TOYOBO, Osaka, Japan), using P3 and P4. Using P5, the His-smt3-F598H was mutated back to His-smt3-ACS $\alpha_{15}$. Then S594H and S594H-GP were constructed using P6 and P7. Primer Pairs were listed in support information (Table S1). In each case, the cloned region of the plasmid was sequenced (JieLi biology, Shanghai Co., Ltd., Shanghai, China) to verify the fidelity of the PCR reactions.

The expression and purification of the mutant proteins were carried out according to the reported methods [17]. The only difference was that the His-smt3 tag was removed by SUMO protease. The imidazole in the elution was removed by dialyzing for three times at $4{ }^{\circ} \mathrm{C}$. The His-smt 3 fusion tag was cleaved upon incubation with SUMO protease for $8 \mathrm{~h}$ at $16^{\circ} \mathrm{C}$, and the smt 3 tags and liberated proteins were separated re-subjected to Ni-NTA column. All proteins were found to be at least $95 \%$ pure based on the denaturing polyacrylamide gels stained with Coomassie Brilliant Blue (Figure S1).

\subsection{Metal Reconstruction and Metal Analysis}

The isolated mutant proteins had a little amount of $\mathrm{Ni}^{2+}$, and the nickel reconstitution of the mutants was carried out by incubation with $\mathrm{NiCl}_{2}$. The $\mathrm{Ni}$-activated proteins were subjected to a G-25 column to remove excessive nickel ions. The Ni-activated proteins were dialyzed three times by dialyzing, respectively, in the presence of $5 \mathrm{mM} 10$-phenanthroline 
(phen) in buffer for $2 \mathrm{~h}$ to remove the labile Nip in the Ni-reconstructed mutant proteins. The excessive phen and $\left[\mathrm{Ni}(\mathrm{phen})_{2}\right] \mathrm{Cl}_{2}$ in the protein solution were removed by $\mathrm{G}-25$ column.

Protein samples for metal analysis were digested with metal-free nitric acid and heated overnight at $65^{\circ} \mathrm{C}$. The denatured samples were diluted with metal-free water to be analyzed on a Pekin-Elmer Optima 3000 DV inductively coupled plasma optical emission spectrometer (ICP-OES).

\subsection{Protein Characterization}

UV-vis spectra were recorded on a HP $8453 \mathrm{UV} /$ Vis spectrophotometer using a quartz cuvette with $1 \mathrm{~cm}$ path length at $25^{\circ} \mathrm{C}$ as reported previously [10]. Low-temperature EPR spectra were recorded with a Bruker EMX X-band spectrometer equipped with an Oxford910 cryostat and ITC-503 temperature controller (Oxford Instruments Ltd., Oxfordshire, UK). All data were analyzed with the Bruker WinEPR software. EPR settings: temperature $2 \mathrm{~K}$, microwave frequency $9.49 \mathrm{GHz}$, microwave power, $20 \mathrm{~mW}$, modulation amplitude $5 \mathrm{G}$. In general, $\mathrm{Ni}^{3+}$ species of the mutant proteins was generated in a 3:1 mixture of buffer solution: glycerol (buffer solution: $50 \mathrm{mM}$ potassium phosphate, $\mathrm{pH}$ 7.4) in a quartz EPR tube [17]. 1 equivalent of $\mathrm{KO}_{2}$ (dissolved using 18-crown-6-ether in DMSO) was added to a $\sim 400 \mu \mathrm{M}$ protein solution, and the mixture was quickly mixed in a vortex mixer and then immediately frozen in liquid nitrogen. The solvent system was checked carefully as controls, and no obvious signals were obtained. EPR simulation was performed with the EasySpin software.

\subsection{Cyclic Voltammetry Assay}

Cyclic voltammetry was performed on a CHI 660A electrochemical workstation (Chenhua, Shanghai, China). A standard three-electrode cell was utilized with a saturated calomel reference electrode (SCE, Kowloon Tong, Hong Kong, China), a Pt wire auxiliary electrode, and a protein/MPA-modified Au disk working electrode $\left(0.2 \mathrm{~cm}^{2}\right)$. MPA-modified Au electrodes were prepared using a previously demonstrated procedure [26]. The freshly prepared Au electrodes were soaked in a $20 \mathrm{mM}$ MPA solution for $1 \mathrm{~h}$. The electrodes were then rinsed with ethanol to remove the no chemisorbed MPA prior to use in electrochemical experiments. NiSOD-like enzyme/MPA-modified Au electrodes were prepared by soaking the MPA-modified Au electrodes in $0.1 \mathrm{mM}$ mutant proteins for $6 \mathrm{~h}$. The as-prepared electrodes were then rinsed with water and stored at $4{ }^{\circ} \mathrm{C}$ when not in use. The supporting electrolyte solution was $0.1 \mathrm{M}$ phosphate buffer solution (PBS) pH 7.0. Cyclic voltammetry was recorded at a scan velocity of $100 \mathrm{mV} / \mathrm{s}$. All potentials were cited versus the normal hydrogen electrode (NHE) using a correction of $+242 \mathrm{mV}$ for the potential of the reference electrode.

\subsection{SOD Activity Assay}

SOD activity assays were performed according to the McCord-Fridovich method using NBT. The xanthine/xanthine oxidase system was used as enzymic source for the generation of $\mathrm{O}_{2}{ }^{-}$in this system. The experiment was performed in a $2 \mathrm{~mL}$ system as reported [17]. The absorption was recorded over a period of $60 \mathrm{~s}$ at $560 \mathrm{~nm}$, and carred out every $5 \mathrm{~s}$ in a kinetic model on HP $8452 \mathrm{UV} /$ Vis spectrophotometer. The SOD-activity (U) is defined as the half-limited reduction of NBT and measured by a reduction in the slope and set relative to the concentration of the substance: $\mathrm{U}=2\left(\mathrm{M}_{\text {control }}-\mathrm{M}_{\text {substrate }}\right) / \mathrm{M}_{\text {control }}$, where $\mathrm{U}$ is the activity unit of the metalloprotein relative to the amount present in the test (given in $\mathrm{U} / \mu \mathrm{mol}$ ). As the mutants contain different ratios of nickel, the finial SOD-activity was calculated according to the amount of $\mathrm{Ni}$-containing protein.

\subsection{Molecular Dynamic Simulation}

The initial structures of these designed mutants were generated based on the X-ray structure of ACS- $\alpha_{15}$ (PDB: 3S2X) by adding the additional amino acids to the N-terminus using program VMD 1.9 (Visual Molecular Dynamics). The conformation of $\left[\mathrm{Ni}^{2+} \mathrm{N}_{2} \mathrm{~S}_{2}\right]$ 
and $\mathrm{N}_{\mathrm{His}}-\mathrm{Ni}$ coordination were defined according to the $\mathrm{X}$-ray structure of native $\mathrm{Ni}$ SOD, with an average bond length of S-N, $2.24 \AA$, N-Ni (in plane), $2.00 \AA$, and N-Ni (in axial), $2.67 \AA$, respectively (PDB: 1T6U). Other parameters were obtained from the classical force field CHARMM27. The psfgen program of NAMD2.8 (Nanoscale Molecular Dynamics) was used to add hydrogen atoms and assign charges to the protein, which was set up according to $\mathrm{pH}$ 7.0. The protein was then solvated in a cubic box of TIP3 water with periodic boundary conditions, which extended $10 \AA$ away from any given protein atom. The protein-water system was first minimized for 5000 steps ( 1 fs per step) using program NAMD 2.8 with conjugate gradient method at $0 \mathrm{~K}$, subsequently equilibrated for 10,000 molecular dynamics steps via an NVT ensemble (where the number of particles N, the volume $\mathrm{V}$, and the temperature $\mathrm{T}$ of the system were kept constant) at $300 \mathrm{~K}$, a procedure similar to model $\mathrm{F} 598 \mathrm{H}$ mutant in our previous study. The system was further minimized for 30,000 steps before analyzing it with VMD 1.9.

\section{8. $p H$ Titration Assay}

Optical and activity $\mathrm{pH}$ titrations were performed over a $\mathrm{pH}$ range of 5 to 9 using $20 \mathrm{mM}$ PBS buffer. The absorption intensity was recorded at the wavelength of $430 \mathrm{~nm}$ for optical pH titration. Before spectrophotometric measurements, each mutant was allowed to incubate in buffer of desired $\mathrm{pH}$ for $1 \mathrm{~h}$ at room temperature to reach equilibrium. The absorbance's dependences on $\mathrm{pH}$ were fitted using the Henderson-Hasselbalch equation.

\subsection{Isothermal Titration Calorimetry (ITC) Assay}

To measure the nickel ion affinity of the F598H variant protein EFG-F598H, Isothermal Titration Calorimetry (ITC) was applied (MicroCal ITC 200, GE healthcare Life Sciences, Pittsburgh, PA, USA) at $25^{\circ} \mathrm{C}$. The protein sample (apo-EFG-F598H, $50 \mu \mathrm{M}$ ) was titrated against $20 \mathrm{mM}$ HEPES buffer ( $\mathrm{pH} 7.4$ ) containing $1 \mathrm{mM} \mathrm{NiCl}_{2}$. Titrations were performed as 25 injections ( $1.5 \mu \mathrm{L}$ each) of a metal stock solution into a protein solution in the sample cell $(200 \mu \mathrm{L})$ of the calorimeter. Each metal injection required a $120 \mathrm{~s}$ relaxation interval between successive injections. The data correction and curve fitting were performed using Origin 7.0.

\subsection{Electro Spray Ionization-Mass Spectroscopy (ESI-MS) Assay}

ESI-MS was performed on an LTQ Orbitrap XL mass spectrometer (Thermo Electron Corp., Bremen, Germany). The purified proteins were subjected to a G-25 column to change the buffer solutions to water and $0.1 \%$ formic acid was added to the protein solutions just before the test. The protein concentrations were $5 \mathrm{mg} / \mathrm{mL}$. The spray voltage was set at $1.6 \mathrm{kV}$ and the heated capillary at $200{ }^{\circ} \mathrm{C}$. The mass spectrometer was operated in positive mode at the mass range 350 1800 Da with resolution of 60,000. The AGC expectation during full-MS was $1,000,000$. The error for the calculated mass is about $\pm 5 \mathrm{Da}$.

\subsection{Crystallography of $F 598 \mathrm{H}$}

$\mathrm{F} 598 \mathrm{H}(\sim 20 \mathrm{mg} / \mathrm{mL})$ was crystallized at $16{ }^{\circ} \mathrm{C}$ with Tris. $\mathrm{HCl}(100 \mathrm{mM}, \mathrm{pH} 9.0) /\left(\mathrm{NH}_{4}\right)_{2} \mathrm{SO}_{4}$ $(1.8 \mathrm{M})$ with a protein/reservoir solution ratio of 1:1 in the crystallization drops. Crystals were flash frozen in liquid nitrogen in the reservoir solution supplemented with glycerol $(20 \%, v / v)$. The crystals diffracted to $2.20 \AA$ at beam line BL17U at Shanghai Synchrotron Facility (SSRF). The nickel absorption edge was determined to be at $8343 \mathrm{KeV}$ by fluorescence scanning. Diffraction data at the nickel peak wavelength $(1.486 \AA)$ were collected with one-degree oscillation widths through a range of $360^{\circ}$. The diffraction data were integrated and scaled by using the HKL2000 package [42]. The nickel atom was determined with the program SHELXD. Then the PHENIX software package was used to solve the structure. Briefly, the Phenix AutoSol was used to refine the locations of substructures, calculate the initial phases, make Density Modifications and build the initial model. After model built using Phenix AutoBuild, 125 of the total 135 residues were successfully built in the initial model. The final model was manually completed by the program Coot and further 
refined by Phenix Refine. The quality of the models was checked using PROCHECK [43]. A summary of data collection and refinement statistics are shown in Table S2. Atomic coordinates and structure factors have been deposited in the Protein Data Bank (PDB: 5GOL). The structural figure was prepared using PyMOL.

\section{Conclusions}

In summary, to functionally convert a truncated acetyl-coenzyme A synthase at $\mathrm{Ni}_{\mathrm{d}^{-}}$ site to a Ni-SOD-like enzyme, we systematically modified the coordination microenvironments of the redox-inactive $\mathrm{Ni}_{\mathrm{d}}$ site. The first strategy is to introduce an axial histidine ligand by mutation to the first coordination sphere of the $\mathrm{Ni}_{\mathrm{d}}$ site. The resulting three mutant proteins obtained Ni-SOD-like activity successfully, although the catalytic activity was much lower than that of native Ni-SOD enzyme. The second strategy is to mimic the $\mathrm{H}$-bond network in the coordination microenvironment of the Ni-SOD active site. A successful mutant EFG-F598H exhibited a $~ 3$-fold increased Ni-SOD-like activity of F598H. The $\mathrm{pH}$ titrations revealed the source of two protons required for forming $\mathrm{H}_{2} \mathrm{O}_{2}$ in the SOD catalytic reaction. The crystal structure of $\mathrm{F} 598 \mathrm{H}$ with an inter-molecular disulfide bond explained the impaired SOD activity caused by cysteine oxidation. Based on all the results, we proposed an outer-sphere catalytic mechanism for the Ni-SOD-like mutants, which provided a basis for the mechanism study of native Ni-SOD. Further studies are ongoing for enhancing the catalytic activity by improving substrate cavity with suitable hydrogen bond networks at the Ni-site coordination microenvironment.

Supplementary Materials: The following supporting information can be downloaded at: https: //www.mdpi.com/article/10.3390/ijms23052652/s1.

Author Contributions: Conceptualization, X.T.; Methodology, Y.W., Y.Z., H.Y. and Y.L.; Validation, X.T.; Formal analysis, H.Y., Y.-W.L. and J.S.; Investigation, Y.W., Y.Z., H.Y. and Y.L.; Data curation, Y.W., Y.Z., H.Y. and Y.L.; Writing-original draft preparation, Y.W. and Y.Z.; Writing-review and editing, X.T.; Supervision, X.T.; Project administration, X.T.; Funding acquisition, X.T. All authors have read and agreed to the published version of the manuscript.

Funding: This research was funded by Natural Science Foundation of China, No. 21977017, No. 21472027, No. 31270869.

Institutional Review Board Statement: Not applicable.

Informed Consent Statement: Not applicable.

Data Availability Statement: The datasets for this manuscript can be obtained from the corresponding author upon reasonable request.

Acknowledgments: We thank the staff of BL18U1/BL19U1/BL19U2 beamlines at the National Center for Protein Science Shanghai and Shanghai and Beijing Synchrotron Radiation Facility, Institute of High Energy Physics, Chinese Academy of Sciences, for assistance during data collection.

Conflicts of Interest: The authors declare no conflict of interest.

\section{References}

1. Fontecilla-Camps, J.C.; Amara, P.; Cavazza, C.; Nicolet, Y.; Volbeda, A. Structure-function relationships of anaerobic gas-processing metalloenzymes. Nature 2009, 460, 814-822. [CrossRef] [PubMed]

2. Huang, M.; Parker, M.J.; Stubbe, J. Choosing the Right Metal: Case Studies of Class I Ribonucleotide Reductases. J. Biol. Chem. 2014, 289, 28104-28111. [CrossRef] [PubMed]

3. Lu, Y.; Yeung, N.; Sieracki, N.; Marshall, N.M. Design of functional metalloproteins. Nature 2009, 460, 855-862. [CrossRef] [PubMed]

4. Petrik, I.D.; Liu, J.; Lu, Y. Metalloenzyme design and engineering through strategic modifications of native protein scaffolds. Curr Opin. Chem. Biol. 2014, 19, 67-75. [CrossRef]

5. Yu, F.T.; Cangelosi, V.M.; Zastrow, M.L.; Tegoni, M.; Plegaria, J.S.; Tebo, A.G.; Mocny, C.S.; Ruckthong, L.; Qayyum, H.; Pecoraro, V.L. Protein Design: Toward Functional Metalloenzymes. Chem. Rev. 2014, 114, 3495-3578. [CrossRef]

6. Bhagi-Damodaran, A.; Hosseinzadeh, P.; Mirts, E.; Reed, J.; Petrik, I.D.; Lu, Y. Design of Heteronuclear Metalloenzymes. In Peptide, Protein and Enzyme Design; Pecoraro, V.L., Ed.; Elsevier: Amsterdam, The Netherlands, 2016; Volume 580, pp. 501-537. 
7. Nastri, F.; Chino, M.; Maglio, O.; Bhagi-Damodaran, A.; Lu, Y.; Lombardi, A. Design and engineering of artificial oxygen-activating metalloenzymes. Chem. Soc. Rev. 2016, 45, 5020-5054. [CrossRef]

8. Lin, Y.W. Rational design of metalloenzymes: From single to multiple active sites. Coord. Chem. Rev. 2017, 336, 1-27. [CrossRef]

9. Schwizer, F.; Okamoto, Y.; Heinisch, T.; Gu, Y.F.; Pellizzoni, M.M.; Lebrun, V.; Reuter, R.; Kohler, V.; Lewis, J.C.; Ward, T.R. Artificial Metalloenzymes: Reaction Scope and Optimization Strategies. Chem. Rev. 2018, 118, 142-231. [CrossRef]

10. Nastri, F.; D'Alonzo, D.; Leone, L.; Zambrano, G.; Pavone, V.; Lombardi, A. Engineering Metalloprotein Functions in Designed and Native Scaffolds. Trends Biochem. Sci. 2019, 44, 1022-1040. [CrossRef]

11. Liu, Y.; Zhu, X.; Wang, F.; Ying, T.; Li, P.; Huang, Z.X.; Tan, X. Probing the role of the bridging C509 between the [Fe4S4] cubane and the $[\mathrm{Ni}(\mathrm{p}) \mathrm{Ni}(\mathrm{d})]$ centre in the A-cluster of acetyl-coenzyme A synthase. Chem. Commun. 2011, 47, 1291-1293. [CrossRef]

12. Liu, Y.; Wang, F.; Li, P.; Tan, X. Insights into the mechanistic role of the [Fe4S4] cubane in the A-cluster \{[Fe4S4]-(SR)-[NipNid]\} of acetyl-coenzyme A synthase. Chembiochem 2011, 12, 1417-1421. [CrossRef]

13. Kung, Y.; Drennan, C.L. A role for nickel-iron cofactors in biological carbon monoxide and carbon dioxide utilization. Curr. Opin. Chem. Biol. 2011, 15, 276-283. [CrossRef]

14. Lindahl, P.A. Acetyl-coenzyme A synthase: The case for a Ni(p)(0)-based mechanism of catalysis. J. Biol. Inorg. Chem. 2004, 9, 516-524. [CrossRef]

15. Wuerges, J.; Lee, J.W.; Yim, Y.I.; Yim, H.S.; Kang, S.O.; Djinovic Carugo, K. Crystal structure of nickel-containing superoxide dismutase reveals another type of active site. Proc. Natl. Acad. Sci. USA 2004, 101, 8569-8574. [CrossRef]

16. Darnault, C.; Volbeda, A.; Kim, E.J.; Legrand, P.; Vernede, X.; Lindahl, P.A.; Fontecilla-Camps, J.C. Ni-Zn-[Fe4-S4] and Ni-Ni-[Fe4S4] clusters in closed and open subunits of acetyl-CoA synthase/carbon monoxide dehydrogenase. Nat. Struct. Biol. 2003, 10, 271-279. [CrossRef]

17. Barondeau, D.P.; Kassmann, C.J.; Bruns, C.K.; Tainer, J.A.; Getzoff, E.D. Nickel superoxide dismutase structure and mechanism. Biochemistry 2004, 43, 8038-8047. [CrossRef]

18. Liu, Y.; Wang, Q.; Wei, Y.; Lin, Y.W.; Li, W.; Su, J.H.; Wang, Z.; Tian, Y.; Huang, Z.X.; Tan, X. Functional conversion of nickelcontaining metalloproteins via molecular design: From a truncated acetyl-coenzyme A synthase to a nickel superoxide dismutase. Chem. Commun. 2013, 49, 1452-1454. [CrossRef]

19. Schmidt, M.; Zahn, S.; Carella, M.; Ohlenschlager, O.; Gorlach, M.; Kothe, E.; Weston, J. Solution structure of a functional biomimetic and mechanistic implications for nickel superoxide dismutases. ChemBioChem 2008, 9, 2135-2146. [CrossRef]

20. Youn, H.D.; Kim, E.J.; Roe, J.H.; Hah, Y.C.; Kang, S.O. A novel nickel-containing superoxide dismutase from Streptomyces spp. Biochem. J. 1996, 318 Pt 3, 889-896. [CrossRef]

21. Herbst, R.W.; Guce, A.; Bryngelson, P.A.; Higgins, K.A.; Ryan, K.C.; Cabelli, D.E.; Garman, S.C.; Maroney, M.J. Role of conserved tyrosine residues in NiSOD catalysis: A case of convergent evolution. Biochemistry 2009, 48, 3354-3369. [CrossRef]

22. Shearer, J.; Zhao, N. [Me4N](Ni(II)(BEAAM)): A synthetic model for nickel superoxide dismutase that contains Ni in a mixed amine/amide coordination environment. Inorg. Chem. 2006, 45, 9637-9639. [CrossRef] [PubMed]

23. Gale, E.M.; Simmonett, A.C.; Telser, J.; Schaefer, H.F., 3rd; Harrop, T.C. Toward functional Ni-SOD biomimetics: Achieving a structural/electronic correlation with redox dynamics. Inorg. Chem. 2011, 50, 9216-9218. [CrossRef] [PubMed]

24. Bryngelson, P.A.; Arobo, S.E.; Pinkham, J.L.; Cabelli, D.E.; Maroney, M.J. Expression, reconstitution, and mutation of recombinant Streptomycescoelicolor NiSOD. J. Am. Chem. Soc. 2004, 126, 460-461. [CrossRef]

25. Mathrubootham, V.; Thomas, J.; Staples, R.; McCraken, J.; Shearer, J.; Hegg, E.L. Bisamidate and mixed amine/amidate NiN2S2 complexes as models for nickel-containing acetyl coenzyme A synthase and superoxide dismutase: An experimental and computational study. Inorg. Chem. 2010, 49, 5393-5406. [CrossRef] [PubMed]

26. Nakane, D.; Wasada-Tsutsui, Y.; Funahashi, Y.; Hatanaka, T.; Ozawa, T.; Masuda, H. A novel square-planar Ni(II) complex with an amino-carboxamido-dithiolato-type ligand as an active-site model of NiSOD. Inorg. Chem. 2014, 53, 6512-6523. [CrossRef]

27. Tian, Y.; Mao, L.; Okajima, T.; Ohsaka, T. Electrochemistry and electrocatalytic activities of superoxide dismutases at gold electrodes modified with a self-assembled monolayer. Anal. Chem. 2004, 76, 4162-4168. [CrossRef] [PubMed]

28. Choudhury, S.B.; Lee, J.W.; Davidson, G.; Yim, Y.I.; Bose, K.; Sharma, M.L.; Kang, S.O.; Cabelli, D.E.; Maroney, M.J. Examination of the nickel site structure and reaction mechanism in Streptomyces seoulensis superoxide dismutase. Biochemistry 1999, 38, 3744-3752. [CrossRef]

29. Leveque, V.J.; Vance, C.K.; Nick, H.S.; Silverman, D.N. Redox properties of human manganese superoxide dismutase and active-site mutants. Biochemistry 2001, 40, 10586-10591. [CrossRef]

30. Fee, J.A.; DiCorleto, P.E. Observations on the oxidation-reduction properties of bovine erythrocyte superoxide dismutase. Biochemistry 1973, 12, 4893-4899. [CrossRef]

31. Shearer, J. Use of a metallopeptide-based mimic provides evidence for a proton-coupled electron-transfer mechanism for superoxide reduction by nickel-containing superoxide dismutase. Angew. Chem. Int. Ed. 2013, 52, 2569-2572. [CrossRef]

32. Tietze, D.; Tischler, M.; Voigt, S.; Imhof, D.; Ohlenschlager, O.; Gorlach, M.; Buntkowsky, G. Development of a functional cis-prolyl bond biomimetic and mechanistic implications for nickel superoxide dismutase. Chemistry 2010, 16, 7572-7578. [CrossRef]

33. Vance, C.K.; Miller, A.F. Spectroscopic comparisons of the $\mathrm{pH}$ dependencies of Fe-substituted (Mn)superoxide dismutase and Fe-superoxide dismutase. Biochemistry 1998, 37, 5518-5527. [CrossRef] 
34. Yamakura, F.; Kobayashi, K.; Ue, H.; Konno, M. The pH-dependent changes of the enzymic activity and spectroscopic properties of iron-substituted manganese superoxide dismutase. A study on the metal-specific activity of Mn-containing superoxide dismutase. Eur. J. Biochem. 1995, 227, 700-706. [CrossRef]

35. Neupane, K.P.; Shearer, J. The influence of amine/amide versus bisamide coordination in nickel superoxide dismutase. Inorg. Chem. 2006, 45, 10552-10566. [CrossRef]

36. Shearer, J. Dioxygen and superoxide stability of metallopeptide based mimics of nickel containing superoxide dismutase: The influence of amine/amidate vs. bis-amidate ligation. J. Inorg. Biochem. 2013, 129, 145-149. [CrossRef]

37. Hanss, J.; Kruger, H.J. First isolation and structural characterization of a nickel(III) complex containing aliphatic thiolate donors. Angew. Chem. Int. Ed. 1998, 37, 360-363. [CrossRef]

38. Harrop, T.C.; Olmstead, M.M.; Mascharak, P.K. Novel folding of N,N'-naphthalenebis(o-mercaptobenzamide) in nickel(II) complexes: Monomeric and trimeric species with unexpected 'butterfly' and 'slant chair' structure. Inorg. Chim. Acta 2002, 338, 189-195. [CrossRef]

39. Kruger, H.J.; Peng, G.; Holm, R.H. Low-potential nickel(III,II) complexes: New systems based on tetradentate amidate-thiolate ligands and the influence of ligand structure on potentials in relation to the nickel site in [NiFe]-hydrogenases. Inorg. Chem. 2002, 30, 734-742. [CrossRef]

40. Neupane, K.P.; Gearty, K.; Francis, A.; Shearer, J. Probing variable axial ligation in nickel superoxide dismutase utilizing metallopeptide-based models: Insight into the superoxide disproportionation mechanism. J. Am. Chem. Soc. 2007, 129, 14605-14618. [CrossRef]

41. Prabhakar, R.; Morokuma, K.; Musaev, D.G. A DFT study of the mechanism of Ni superoxide dismutase (NiSOD): Role of the active site cysteine-6 residue in the oxidative half-reaction. J. Comput. Chem. 2006, 27, 1438-1445. [CrossRef]

42. Adams, P.D.; Afonine, P.V.; Bunkoczi, G.; Chen, V.B.; Davis, I.W.; Echols, N.; Headd, J.J.; Hung, L.W.; Kapral, G.J.; Grosse-Kunstleve, R.W.; et al. PHENIX: A comprehensive Python-based system for macromolecular structure solution. Acta Crystallogr. Sect. D Biol. Crystallogr. 2010, 66, 213-221. [CrossRef] [PubMed]

43. Laskowski, R.A.; Macarthur, M.W.; Moss, D.S.; Thornton, J.M. Procheck-A program to check the stereochemical quality of protein structures. J. Appl. Crystallogr. 1993, 26, 283-291. [CrossRef] 